\title{
Fracturing Forms: Recuperation and Simulation in The Golden Notebook
}

\begin{abstract}
CRiTicism on The Golden Notebook has largely been concerned to understand it as a work of literature, removed from its social context. Yet The Golden Notebook is deeply concerned with the relation between cultural formation, artistic expression, and individual identity. It foregrounds many of the concepts that are central to the new scientific paradigms-chaos and information, unpredictability and fragmentation-identifying them as crucial to the evolution of new forms of literature and subjectivity. Although Doris Lessing almost certainly did not know about chaos theory, she was keenly aware of the impact that proliferating information was having on traditional art forms. She also realized that these changes were bound up with the problematic relation of local sites to global perspectives. The Golden Notebook thus represents a development parallel to chaos theory. It testifies to how highly charged the idea of chaos had become by the mid-twentieth century.

The Golden Notebook (1962) represents a cusp in Doris Lessing's works, a transitional moment in which chaos is breaking open old forms but before it has catalyzed the emergence of "a new way of looking at life." And yet the fractured form points to the creation of something new-although whether this something is a novel remains problematic. Why a new form should be necessary is intimated by Anna as she writes about her dissatisfaction with her novel


The Frontiers of War. "The novel has become a function of the fragmented society, the fragmented consciousness. Human beings are so divided, are becoming more and more divided, and more subdivided in themselves, reflecting the world, that they reach out desperately, not knowing they do it, for information about other groups inside their own country, let alone about groups in other countries" ( $p$. 6I). To trace the connections between fragmentation and the changed novelistic function that Anna senses, it will be helpful to recall the distinction Walter Benjamin makes between the story, the novel, and information (I 969:83-I Io). ${ }^{1}$

According to Benjamin, the story had its beginnings in craft labor. He conjures up an image of a storyteller spinning his tale while his listeners spin and weave cloth, with the rhythm of the story and the rhythm of the work interpenetrating. The purpose of the story is to give counsel, Benjamin says, which presupposes a physical community that speaker and listener cohabit, and more profoundly a community of values they share. The novel is distinguished from the story in being written. Following Lukács, Benjamin sees the novel as signifying a "transcendental homelessness" (p. 99), an essential isolation reflected in its attempt to grasp the meaning of life. Since this meaning can be apparent only in retrospect, after the whole shape of a life is known, the novel positions itself ontologically as a remembrance. The story, by contrast, addresses itself to how the listener can enrich his life as he lives it. Rather than try to grasp the whole, it contributes to the ongoingness of process.

The decay of community implicit in the contrast between story and novel progresses further with information. Unlike either story or novel, information has no depth, no spaces where the listener or reader may enter to supply her own interpretation. On the contrary, Benjamin says, the primary requirement for information is that it be " 'understandable in itself'" (p. 89), fully explained and immediately accessible. Whereas story presupposes a shared context and commu-

'I am indebted to Alan Swingewood for drawing the connection between Benjamin's theory and Lessing in his article "Structure and Ideology in the Novels of Doris Lessing" Sociology Review Monograph: The Sociology of Literature 26 (1978): $38-54$. Swingewood also notes that the emergence of a novel of information is connected with the disappearance of the "problematic hero" in Lessing's fiction and with her replacement by a "collective hero and conceptual structure" (p. 4x). 
nal values, information can be transported into any context. The incongruous juxtapositions of newspaper fillers illustrate the disappearance of shared, stable contexts: how many camels were born last year in Saudi Arabia, how many months an elephant carries its young before parturition. What connection does this information have to the reader, and what contexts does it presuppose and create? According to Benjamin, the triumph of information over story and novel bespeaks the death of experience, for to him experience means something more than facts or explanations. It signifies the texture of life created from a wealth of small shared moments, the unspoken and unconscious expectations that form the fabric upon which the figures of story are embroidered. In the absence of these shared contexts, experience is incommunicable. Facts can be told; events can be narrated; but experience cannot be shared, for the cloth out of which it is woven has been destroyed.

The Golden Notebook records the end of story through Anna's failure to tell a story, linking it to a fragmentation so profound that even the remembrance of experience is lost. Throughout, Anna senses that words are losing their meaning; "the gap between what they are supposed to mean, and what they in fact say seems unbridgable" (p. 300). The retrospective shape of the novel haunts her as she tries to write about the breakup of her five-year relationship with her married lover, Michael, using the characters Ella and Paul. Musing on how the ending of the affair distorts the telling of it, Anna writes that the "trouble with this story is that it is written in terms of analysis of the laws of dissolution of the relationship between Paul and Ella. I don't see any other way to write it. As soon as one has lived through something, it falls into a pattern. And the pattern ... is untrue. Because while living through something one doesn't think like that at all." Anna wonders if she should try to tell her story by recording every detail of two days, one near the beginning and another near the end, to convey the sense of process. But she realizes that "I would still be instinctively isolating and emphasizing the factors that destroyed the affair. It is that which would give the thing its shape. Otherwise it would be chaos. . . Literature is analysis after the event" (pp. 227-228).

Dismayed by "the thinning of language against the density of our experience" (p. 302), Anna turns to visual media as truer modes of 
expression, imagining the stories she tells as films rather than novels or stories. But even films desert her when she dreams that The Frontiers of War has finally been made into a movie. She complains to the director that the film has falsified her experiences. More than that, it has displaced them, for after seeing the film she finds that she can no longer remember how Maryrose held her head or Paul smiled (pp. 524-525). Later, the film moves inward and an imagined "projectionist" screens it within her mind. Thinking how wrong it is, Anna is devastated when she reads the credits and finds that she is the director. The problem thus goes deeper than language, deeper even than sensory perception. At its root is a fragmentation of the social context reflected in the four notebooks Anna keeps-black for her memories of her African experiences, red for her encounters with the British Communist Party, yellow for the stories she makes from her experiences, blue for her record of the experiences themselves. The "Free Women" sections do not, as they may at first seem to do, succeed in creating a metacontext into which all the other contexts may fit. Rather, they represent yet another partial context - the traditional realistic novel that is no longer able to contain or express all of the fractured sites of Anna's consciousness. Increasingly Anna feels that she cannot capture the truth of her experiences in any of these modes. The failure of the film confirms that the gap between reality and representation is unbridgeable, for it implies that the person she was cannot communicate with the person she is, so that her experience is incommunicable even to herself.

Under this pressure, the function of the novel necessarily changes. If the experiences that constitute one's past cannot be shared even with oneself, there can be no question of representing through remembrance the shape of a life. Within The Golden Notebook, a novel of sorts still exists in the "Free Women" sections, but it is punctuated by the notebook entries. Within the notebooks, novelistic fragments also exist. But as the narrative continues, stories increasingly give way to information. The black notebook ends as a

Patrocinio P. Schweickart, in "Reading a Wordless Statement: The Structure of Doris Lessing's The Golden Notebook," Modern Fiction Studies 31 (1985): 263279, also notices the problematic nature of the novels within the novel, calling The Golden Notebook "a collection of canceled novels, novels Lessing had refused to write but nevertheless had written" (p. 274). 
collage of newspaper clippings. A similar fate befalls the red notebook. The yellow notebook fragments into pieces of stories spliced together into a pastiche. The blue notebook, which Anna dedicates to writing about events as they happen without making up stories about them, continues to record information from her fragmenting sensibility after the other notebooks have stopped. It too ends; yet its final page marks a turning. Having drawn heavy black lines across the pages of the other notebooks, Anna resolves to write no longer in separate texts, but to put "all of myself in one book" (p. 607).

This will toward synthesis drives her into a direct confrontation with the information age. She cuts out newspaper articles about horrific events all over the world-rapes, tortures, murders, genocideand for as high as she can reach, papers the walls of her room with them. She spends her days going about the room, reading clippings and putting up more. By physically locating this disparate information within her living space and by absorbing it within herself, she succeeds in creating a common context for it. The price she pays is that she must now live in the space she has created. She is the common denominator for the information she scans; if her attention wanders or if she leaves the room, it degenerates again into fragments. "It was as if she, Anna, were a central point of awareness, being attacked by a million unco-ordinated facts, and the central point would disappear if she proved unable to weigh and balance the facts, take them all into account" (p. 649). Tortured by the information on her walls but unable to break free from her feeling that she must bring it together into a whole, Anna contemplates beginning to paper a second room with clippings. By extension, one could imagine a world in which the Derridean maxim that there is no outside to the text would be literally true. From her doubly interior position within the text/room, Anna realizes that her quest for wholeness (which is also Lessing's quest for a novel about Anna) has led her into chaos. She is surrounded by it; more than that, she has become it.

As an emblem, the text/room reveals that the attempt to see things whole entails recognition that the individual psyche is bound to the culture by feedback loops that run through textuality. The texts produced by the culture and by the individual, produce them in turn. If 
the texts of a culture are profoundly fragmented and obsessed with death, so is the text that is the individual. And if one wants to grasp the whole, as in a traditional novel, one must write about fragmentation and chaos, which is to say, one must write information and not a novel. This is the paradox at the center of The Golden Notebook, whose fractured form signifies that it is a novel under erasure, attempting to represent the shape of the whole by meditating upon all the complex reasons why wholeness is impossible at this time.

\section{The Limits of Analogy: On the Cusp}

In Lessing's I97I Introduction to The Golden Notebook, she complains that the central importance of the novel's structure had been overlooked, asserting that it constitutes a "wordless statement" designed "to talk through the way it was shaped" (p. xiv). Since Lessing's Introduction, a number of essays have appeared emphasizing the significance of the structure and exploring its relation to the novel's central themes. ${ }^{3}$ Several years ago Betsy Draine pointed out that Lessing's text, despite its concern with disorder, is highly symmetric (1980:32). Draine represented the order as follows (from left to right $).^{4}$

Barbara Bellow Watson, "Leaving the Safety of Myth: Doris Lessing's The Golden Notebook," in Old Lines, New Forces, ed. Robert K. Morris, pp. I 2-37 (New York: Rutherford, I 976), comments on the tension between order and chaos in the structure, asserting that "nothing could be more orderly, nothing could be more a response to chaos" (p. I6). Herbert Marder, in "The Paradox of Form in The Golden Notebook," Modern Fiction Studies 26 (1980): 49-54, interprets the paradox of a formed formlessness as an embodiment of the mystical insights Anna has in "The Golden Notebook" and "Free Women 5." Anne M. Mulkeen, ii "TwentiethCentury Realism: The "Grid' Structure of The Golden Notebook," Studies in the Novel 4 (1972): 26I-274, interprets the structure spatially, as a "crisscrossing of a multiplicity of viewpoints with a multiplicity of events and issues, near and far, through a series of stages in time" (p. 262). Schweickart, in "Reading a Wordless Statement," stresses the "articulated" nature of the structure, in the sense that it is "cracked, broken in pieces, and, at the same time, hinged, held together by foldingjoints" (p. 268). Betsy Draine gives a subtle and complex reading of the form as typical of postmodernism. Draine sees the fractured form as a response to the "dynamic interplay of order and chaos" (I980:31), and she charts this interplay through the tension between nostalgia and irony within the narrative.

${ }^{4}$ The structure is actually more complex than this scheme recognizes, but this notation is useful for the moment. Later I will refine and modify it. 
242 The Figure in the Carpet

$\begin{array}{lllll}\text { Free } & \text { Black } & \text { Red } & \text { Yellow } & \text { Blue } \\ \text { Women 1 } & \text { Notebook } & \text { Notebook } & \text { Notebook } & \text { Notebook } \\ & 1 & 1 & 1 & 1 \\ \text { Free } & \text { Black } & \text { Red } & \text { Yellow } & \text { Blue } \\ \text { Women 2 } & \text { Notebook } & \text { Notebook } & \text { Notebook } & \text { Notebook } \\ & 2 & 2 & 2 & 2 \\ \text { Free } & \text { Black } & \text { Red } & \text { Yellow } & \text { Blue } \\ \text { Women 3 } & \text { Notebook } & \text { Notebook } & \text { Notebook } & \text { Notebook } \\ & 3 & 3 & 3 & 3 \\ \text { Free } & \text { Black } & \text { Red } & \text { Yellow } & \text { Blue } \\ \text { Women 4 } & \text { Notebook } & \text { Notebook } & \text { Notebook } & \text { Notebook } \\ & 4 & 4 & 4 & 4\end{array}$

The Golden Notebook

Free Women 5

It is immediately obvious that the structure is recursive, cycling through each of the "Free Women" sections and four notebooks in turn, until the symmetry is broken with the part named after the whole, "The Golden Notebook." Just as there are four notebooks, so there are four recursions before this bifurcation is reached. Given these symmetries, it is tempting to think of the structure as bringing order out of chaos. Such a reading would argue that The Golden Notebook functions like a self-organizing system, with the onset of chaos precipitating a reorganization of the text at a higher level of complexity.

In my view this reading ought to be resisted. The analogy with chaos theory is compelling. It is also subtly misleading if it leads us to read The Golden Notebook retrospectively. From a retrospective view, with knowledge of the paths that were in fact taken in the development of chaotics, earlier works that embody some but not all of its features are seen as imperfect avatars pointing toward later developments, as though there were some inevitable and necessary progressions these events must follow. For writers struggling to conceptualize new ideas before they crystallized into paradigms, however, it would not be clear that the situation consisted of developments, that these developments could be placed along a line, or that this line was a path pointing in a new direction. As a text located at or near a transformation in paradigms, The Golden Notebook almost certainly contains possibilities that would be suppressed if it 
were fixed through coordinates that became points of reference only after it was written.

In juxtaposing The Golden Notebook with chaos theory, then, I do not intend to argue that it embodies a recursive structure in the same sense chaos models do. One of the major contributions of chaos theory has been to provide a set of ideas that people can use to think with when they confront the apparent paradox that chaos makes order possible. Lessing did not have access to these ideas when she wrote The Golden Notebook. Consequently, the problems involved in wresting order from chaos seem to her more intractable and less susceptible to rational analysis than they would to someone whose thought has been formed by chaos theory. The recursive structure of The Golden Notebook does share certain general characteristics with chaos models, including the tendency to magnify latent instabilities and to constitute the relation between local sites and global perspectives as problematic rather than self-evident. But Lessing's text differs significantly from the sciences of chaos in its vision of how order and disorder relate to each other.

This complex relation is suggested by two complementary dreams in The Golden Notebook about spatial fragmentation and unity. In the first, Ella dreams of the house in which Paul lived with his wife, Muriel. Ella imagines that she now lives in "the ugly little house, with its little rooms that were all different from each other." She attempts to unify the house by redecorating, but finds that "it was holding together precisely because each room belonged to a different epoch, a different spirit" (p. 225). The dream inscribes the belief that fragmentation is necessary to prevent a collapse into chaos. At the same time, the fractured contexts of the rooms make coherence impossible. Fragmentation is thus both a symptom of chaos and a defense against it.

Later Anna dreams that she is looking down at the globe covered by a "web of beautiful fabric stretched out." The fabric glows with colors representing the various countries-red for the Soviet Union, black for Africa, and so on. As she watches, the colors melt and flow into each other, forming "one beautiful glittering colour, but a colour I have never seen in life." Feeling "unbearable happiness," she realizes that the "world was slowly dissolving, disintegrating and flying off into fragments, all through space, so that all around me 


\section{The Figure in the Carpet}

were weightless fragments drifting about. . . The world had gone, and there was chaos. I was alone in chaos." Unable to catch the meaning of the dream before it vanishes, she remembers only the phrase "somebody pulled a thread of the fabric and it all dissolved" (p. 299). The dream suggests that wholeness and chaos are very close;' all that stands between them is a loose thread. Unity is thus both the opposite of chaos and the prelude to it.

Taken together, the two dreams make a larger statement. Ella's dream expresses the awareness that what is taken for global order in classical paradigms is in fact only the partial order that each room possesses when considered by itself. As long as one is content to stay within a single room (each belonging, Ella says, to a "different epoch, a different spirit"), one can console oneself with the generalizations that Lessing, in her essays written during this period, consistently labels "parochial." But when one attempts a transcendent perspective such as Anna achieves for a moment in her dream, it is unclear whether the larger picture will cohere into a mystical unity or disintegrate into dissolution and chaos. The effect is very much like what Anna feels in her dream, a complex undecidability that hovers just outside the horizon of comprehensibility.

This effect is quite different than that conveyed either by chaos theory or by deconstruction, each of which is (like Lessing's text) centrally concerned with disorder. Although some "fuzzy" regions always remain within maps of chaotic systems, chaos theory provides a model for the mingling of order and disorder which is entirely rational and deterministic. As we saw earlier, the commitment to rationality and to a noncontradictory global theory is one of the important differences between chaos theory and deconstruction. Deconstruction, for its part, has renounced the possibility embodied in Anna's dream, that a transcendent viewpoint from which the whole makes sense can be achieved. In The Golden Notebook, the tension between order and disorder has been neither rationalized, as it is in chaos theory, nor sharpened into an aporia, as it is in deconstruction. Rather, chaos and order mirror each other, making the text's stance toward them undecidable in a way that is distinctly its own. Later I shall return to explore the implications of this reflexivity for

'See, for example, Lessing, I974:17. 
the peculiar ending of Lessing's text. For the moment, I want to emphasize that because The Golden Notebook is on a cusp, it can keep in suspension possibilities that later will be forced into one path or another when the new paradigms become fully articulated.

\section{Disiunctions and Recursions: Global Visions and Local Politics}

The two dreams related above are characteristic of Ella and Anna, in that they show Ella's concern with the local and domestic, Anna's with the global and public. Ella is Anna's fictional creation (just as Anna is Lessing's), and her anxieties are typically weaker, more conventional versions of Anna's concerns. Anna is worried about global destruction, Ella about clashing wallpaper. Like Ella, Anna is caught in a love triangle with her married lover and his wife; but she is never reduced so completely to the local as Ella is. Running alongside her account of her affair with Michael are her meditations on her political activities in Africa and her experiences with the British Communist Party. However, the distinction between Anna and Ella is not merely that Ella is Anna writ small. Part of Anna's problem is that she cannot see how to connect the domestic and public, the local and global. In separating off a part of herself into Ella, Anna practices fragmentation as a strategy of containment against chaos, just as Ella does in her dream.

The disjunction between the local and global is one of Lessing's major themes, appearing in different guises in the various notebooks. In the blue notebook, it manifests itself in Anna's belief that she fell in love with Michael because he was a "real man," calling forth all of her response as a "real woman." For Anna, the proof of these essentialist ideas is the vaginal orgasm, which she stoutly defends as an infallible sign that the love she feels is real. Yet on September I7, I954, the day she resolves to write everything down just as it happens, she records that Michael awakes and takes her sexually because he hears Janet moving in the next room. She tries to reason away her resentment at Michael's jealousy of her child, asserting that "the resentment, the anger, is impersonal. It is the disease of women in our time" (p. 333). Nevertheless, when they are 
finished, Anna feels resentment that is "suddenly so strong I clench my teeth against it" (p. 334). She tries to make the best of the situation, telling herself that the "two personalities-Janet's mother, Michael's mistress, are happier separated. It is a strain having to be both at once" (p. 336). Ironically, this separation ensures that even if Michael were willing to leave his wife (and he is not), Anna and her child could not live an integrated life with him. Living whole would require Anna to confront Michael with her anger. She understands that if this confrontation were to occur, it could not be confined to the personal level. Behind her anger loom the assumptions of a sexist society, just as behind his patronizing tone lies the tortured history of mid-twentieth-century Europe, including a family killed in Nazi death camps and friends murdered in Prague by Communists. Paradoxically, fragmentation is necessary because everything is connected.

Anna's problems with Michael are rendered more problematic and intense by the fractured contexts in which she lives. When Anna refuses to take her anger seriously because "it is the disease of women of our time," she is caught in the disjunction between her immediate reality and her global analysis. Avoiding confrontation, she reassures herself that her relationship with Michael has a core of reality because the stereotypical responses she uses to constitute it are real. However, these responses reinscribe the very cultural history that she seeks to escape when she insists they are genuine and spontaneous expressions of her deepest self. To prevent these contradictions from surfacing, she uses suppression and fragmentation. Refusing to think about what Michael's alienating and alienated comments signify, she finds her deepest pleasure in cooking for him, in part because cooking does not engage her critical analytic self.

The problem with this reading is that it makes it sound as if Lessing intended to expose the contradictions Anna does not see. Ellen Morgan, in her excellent article "Alienation of the Woman Writer in The Golden Notebook" (1973), has shown that Anna's refusal to criticize Michael's jealousy is part of a pervasive pattern in The Golden Notebook in which women negate their own responses when they are critical of men. She draws the almost unavoidable inference that such attitudes are also Lessing's (p. 480). The consistency with which double standards for men and women appear in 
The Golden Notebook and elsewhere in Lessing's writing has led Marion Vlastos Libby to say plainly, "Doris Lessing is not a feminist, and The Golden Notebook is not a feminist novel" (1974:106). I agree with these conclusions; as Morgan and Libby argue, there is every indication that Lessing sympathizes with Anna's viewpoint. In her I97 I Introduction, for example, when Lessing scolded her readers for missing what she regarded as the point of her book, she set up feminist readings of the text in opposition to the themes of wholeness and fragmentation. Lessing's inclination to bracket off feminist issues, as if they were beside the point, suggests that she has less insight into the way gender construction relates to fragmenting contexts than the recursive symmetries of her text may suggest.

Yet she also creates women characters strong enough to be, as Libby says, "oddly at variance with the qualities revealed in their other functions in life-with their independence and strength and above all with their extraordinarily acute perception of the world" (p. I09). The recursive structure is an important factor in reconciling the tensions between Lessing's strong women characters and her antifeminist presuppositions, for it occludes as well as reveals correlations between different sites. In Ella's dream, fragmentation is identified as an obstacle to unified understanding. At the same time, the fragmented text allows different degrees of awareness to coexist, held as it were in suspension by the recursive structure. The result is a text fractal in its complexity, with areas of clear symmetry intermixed with other areas of suggestive but fuzzy replication. As the narrative scrolls through the various notebooks, the same problems and issues reappear at different sites. How clearly they come into focus at each site depends largely, however, on the modality of the site.

The red notebook, with its thrust toward global understanding and public action, has none of the obfuscations Anna practices in the bedroom. Here the relation between fractured contexts and the local/global split comes plainly into view. Anna says that she decided to join the British Communist Party because she felt the "need for wholeness, for an end to the split, divided, unsatisfactory way we all live" (p. I6I). Yet joining the party "intensified the split" (p. I6I), for in the wake of revelations about Stalin's regime, party gatherings splintered into factions. As attempts to overcome contradictions 
within the Party give rise to more contradictions, the atmosphere of party meetings edges toward hysteria. Anna recognizes the feeling from her recurring dream about the figure whom she calls joy-inspite (p. 482). The dream figure, who appears in increasingly humanoid and familiar form as Anna comes closer to breakdown, is chaos incarnate. His appearance signals that, although fragmentation may initially be able to contain chaos, eventually it facilitates and accelerates the crackup toward which Anna and apparently the entire society are headed.

The yellow notebook manages to be at once more archetypal and trite than the blue notebook. The yellow notebook contains Anna's novel "The Shadow of the Third," which fictionalizes Anna's relationship with Michael in Ella's affair with Paul. The title refers only obliquely to Anna's relation to these two characters. Inside the novel the third is Paul's wife, Muriel, or more precisely Ella's projected image of Muriel. Claire Sprague, in "Doubletalk and Doubles Talk in The Golden Notebook" ( 1982 ), notes that patterns of twos and threes are pervasive in The Golden Notebook, constituting an elaborate play on doubles and projected selves. Aside from their psychological interest, these patterns are significant because they show unified contexts breaking up and re-forming into increasingly complex configurations. As two people are aligned against a third, then as a single person splits into two and one of these parts splits further to make a third, the fragmentation becomes extremely complex. It recalls the fracturing contexts of the British Communist Party, as well as the shifting triad of Molly, Anna, and Mrs. Marks, the psychiatrist whose name suggests that her Freudian generalizations are like Marxist analysis in their refusal to recognize the importance of local differences.

In the black notebook, the personal and public intermingle as Anna recalls how futile and contradictory were the efforts of the socialist group she joined in Africa. Dedicated to looking "at things whole and in relation to each other" (as Lessing remarks of Marxism in her Introduction, p. xiv), the group quickly split in two, then further splintered into factions within the subgroup headed by Willi, Anna's "official" partner. In retrospect, Anna can see how ironically ineffectual the group was. Following Marxist doctrine, they delared that the initiative for overcoming racism should come from the pro- 
letariat, which in this case meant local labor unions. Black labor unions did not exist, however, because blacks were not allowed to organize, and the white unions were even more racist than most of the society. Change, when it came, would be led by black nationalists. But the group disapproved in principle of nationalist movements, viewing them as a "right-wing deviation" (p. 90). Divorced from the realities of the situation, the group began to retreat from public action to private escape at the Mashopi Hotel.

As Anna moves deeper into her recollections, the black notebook becomes a kind of counternovel to her first novel, The Frontiers of War, which we know only through her parodic summaries and comments about it. In this counternovel, Anna recounts how the contradictions inherent in the group's situation exploded when Paul Blackenhurst, in a gesture that combined comradeship and arrogance, befriended Jackson, the Boothbys' black cook. As a result Jackson was fired, and he was forced to take a job where he would not be able to keep his family with him. When Anna expressed dismay, Willi pointed out that Jackson had held exceptional privileges and that most black men were not so lucky. "But I happen to know Jackson and his family," Anna objected, adding, "I can't believe what you say." Willi responded, "Of course you can't. Sentimentalists can never believe in anything but their own emotions" (p. ${ }_{4} 8$ ). For Willi, only the global counts; the local does not matter. ${ }^{6}$

If the problem were merely a lack of connection between the local and the global, communicating links between them could perhaps be forged. The group's response to the African situation, for example, might have been corrected if they had started with local conditions and built up toward generalizations, rather than trying to impose a global theory onto the situation. One could imagine that they might have contacted the black nationalists and centered their efforts on helping them, rather than vainly looking to the labor unions. A similar argument could be made about Anna's personal relationships.

'This attitude is caricatured later by Molly's husband, Richard, who remarks that if he were the head of a secret police and given the task of identifying all the communists in the country, he would offer to set them up in a small health clinic in Africa. All the communists, he maintains, would say no. Although Richard has more than a few faults of his own, his analysis is acute enough to force Anna into an uncomfortable moment of recognition. 
She judges her experiences with men according to a Platonic ideal that she holds in her head. If the relationship does not immediately conform to her idea of what it should be, she dismisses it as secondrate or not "real." The notion that one could build intimacy, that intimacy is the result of and not the precondition for shared experience, seems not to occur to her until she meets Saul Green, and then it takes a psychotic form. Like the socialist group in Africa, Anna rejects local reality because it does not conform to her global expectations.

Another version of the problem is to see people as merely symptomatic of their time, without individual personality. For example, Anna sees Nelson and his frenetic wife as the victims of fractured contexts that make wholeness impossible. She says to Mother Sugar that there is a "crack in that man's personality like a gap in a dam, and through that gap the future might pour in a different shapeterrible perhaps, or marvellous, but something new-" (p. 473). The perception is finely tuned. The scene with Nelson, his wife, and his friends at the party recalls Andy Warhol's quip that the essence of postmodernism is being hyper and bored. Through the surface of the boredom, crises keep erupting, fueled by the tremendous internal pressure created by fear of global destruction. The inscription of the global into these people overwhelms them as individuals, making it impossible for Anna to relate to them as anything other than symptoms of a common malaise. In a more conventional way, Ella senses the same thing about Cy Maitland. Yet both Anna and Ella remain confident that somewhere a "real man" exists who is so essentially himself, so sure of his identity as a man, that they will be able to respond to him as "real women" and thus be saved from being merely expressions of their time.

The problem, then, is not so simple as forging links between the local and global, for the global collapses into the local, just as the local reinscribes the global. In the last recursion through the blue notebook before the pattern is broken and a new kind of symmetry appears, Anna experiences a nostalgic glimpse of how the local/ global problematic might be resolved if mediating links could be constructed. Returning to a childhood fantasy, she imagines herself playing "the game." First "I create the room I sat in, object by object, 'naming' everything, bed, chair, curtains, till it was whole in my 
mind, then move out of the room, creating the house, then out of the house, slowly creating the street, then rise into the air, looking down at London . . . but holding at the same time the room and the house and the street in my mind, and then England . . . then slowly, slowly, I could create the world." Having attained a position in space from which she could see the vast panorama of the cosmos, she would "try to imagine at the same time, a drop of water, swarming with life, or a green leaf. Sometimes I could reach what I wanted, a simultaneous knowledge of vastness and of smallness" (p. 548). It is significant that Anna's approach to this knowledge is through a truer naming, and that the naming comes out of a heightened individual sensitivity. The naming game implies that the local/global split could be resolved if she (and we) could break through to a purer use of language by practicing a more intense and aware subjectivity.

\section{Subjectivity and Chaos: The Question of Form}

In The Golden Notebook, the ordering principle that keeps chaos at bay is critical and analytical consciousness. Recall, for example, Anna's belief that her consciousness is the focal point that alone can provide the synthesizing perspective necessary to bring chaotic information into a semblance of order. However, the attempt by an individual consciousness to resolve the local/global split is complicated, because subjectivity itself is necessarily local and global, in the sense that it is at once intensely personal and an expression of its culture.

Subjectivity is a highly charged issue for Lessing. As a Western writer with communist sympathies, she is torn between locating the springs of art in an individual consciousness and locating them in a collective spirit. Anna, scanning material published in communist countries to find if it is suitable for British audiences, finds most of the writing "bad, dead, banal." She feels "forced to acknowledge that the flashes of genuine art are all out of deep, suddenly stark, undisguisable private emotion" (p. 349). She recalls a lecture on medieval art in which she told her audience that "art during the Middle Ages was communal, unindividual; it came out of a group consciousness. It was without the driving painful individuality of the art of the bourgeois era. And one day, we will leave behind the driving 
egotism of individual art. . . Art from the West . . becomes more and more a shriek of torment from souls recording pain" (p. 350 ). In the middle of the lecture, however, she started to stammer. "I know what that stammer meant," she declares, and thereafter gives no more lectures on art. Lessing quotes the passage in her $197 \mathrm{I}$ Introduction, adding that Anna stammered because she was evading the recognition that "there was no way of not being intensely subjective; it was, if you like, the writer's task for that time" (p. xiii). On the one hand, Lessing implies that we believe we are self-determined individuals only because our culture makes us think so. On the other, we can understand our culture only if we plunge into the subjectivity it has inscribed within us.

In her Introduction, Lessing says that the way out of preoccupation with the "tiny individual who is at the same time caught up in such an explosion of terrible and marvellous possibilities, is to see him as a microcosm and in this way to break through the personal, the subjective, making the personal ... into something much larger: growing up is after all only the understanding that one's unique and incredible experience is what everyone shares" ( $p$. xiii). This resolution, like Anna's lecture, is evading something. If the individual is merely an expression of the culture, then the spark of "suddenly stark, undisguisable private emotion" that Anna identifies with "genuine art" has no meaning. A similar evasion occurs in Lessing's essay "The Small Personal Voice." There Lessing says she holds "the view that the realist novel, the realist story, is the highest form of prose writing" (1974:4). In pondering what it is that draws her to the great novels of the past, she admits that "I was not looking for a firm reaffirmation of the old ethical values, many of which I don't accept; I was not in search of the pleasures of familiarity. I was looking for the warmth, the compassion, the humanity, the love of people that ... makes all these old novels a statement of faith in man himself" (p. 6). At the same time, "if one is going to be an architect, one must have a vision to build towards, and that vision must spring from the nature of the world we live in." (p. 7). How can the writer simultaneously express her culture and position herself above it, directing it into new paths? The conundrum suggests that the tension between the individual and the collective is not so easily resolved as Lessing asserts. 
What Lessing circles around but never directly confronts is the possibility that the microcosm/macrocosm correlation between the individual and the culture may itself be an artifact of bourgeois individuality. As we saw in chapter 8 , received ideas about Western individuality were transported into scientific and mathematical models during the Enlightenment through the assumption that complex objects could be represented as collections of autonomous units moving along a continuous time line. It is no accident that in these models one can move easily from the individual unit to the global system; such a movement is possible because the assumptions used to constitute the individual unit are replicated in the assumptions used to construct the system. In the new paradigms, movement up from the individual unit to the system, or down from the system to the individual unit, is no longer an assumed characteristic but a focus for inquiry. Lessing oversimplifies when she suggests that one can resolve this problematic simply by regarding the individual as a microcosm of the global system, for such movement is possible or easy only under a narrow set of conditions. More to the point, she reduces the tensions embodied in her text to a formulation far too neat to encompass their unruly complexities.

The Golden Notebook (as distinct from Lessing's representation of it) presents two different enactments of how individual sensibility and collective spirit relate. In the first, global vision and local experience are joined through heightened subjectivity. Because no fundamental changes are transacted in the way human consciousness is constituted or represented, this enactment defuses the more radical implications of a collapse into chaos. In the second enactment, the split between local and global mounts in intensity until it forces a crisis, from which emerges a text that may appear to be the same as the previous writing but in fact operates according to very different premises. These two enactments represent a profound ambivalence toward the transforming significance of chaos as a new paradigm. At issue is whether chaos can be contained within old forms of expression and representation, or whether it will precipitate a seachange in human experience and art. In her later works, Lessing increasingly took the second path, welcoming and calling forth the transformative power of chaos. But in The Golden Notebook both possibilities are active; both call for belief and commitment. The 
result is a text that is enormously complex because it is balanced between two paradigms, partaking of both and reducible to neither.

This complexity is encoded within the novel's form. On the one hand, the form demonstrates the failure of the novel to cohere, consisting as it does of fragments spliced together. Yet the symmetry suggests that some kind of reorganization takes place in the inner "Golden Notebook," which ought then to be apparent in the final "Free Women" section. In this reading, The Golden Notebook as a whole would possess the coherence that eludes its fragmented parts, for it chronicles the emergence of a new mode of integrated experience and, presumably, a new way of writing. Whether we think that this reorganization has in fact occurred depends in part on who we think is writing the text.

As Joseph Hynes has pointed out in his meticulous study "The Construction of The Golden Notebook" (I973), the answer to "Who writes this text?" is not obvious. In one sense, of course, Lessing writes it; but within the text itself, Anna is the author. Which Anna? As Hynes observes, several versions of Anna are inscribed in the four notebooks and the "Free Women" sections. Moreover, the text we have before us is neither the notebooks themselves nor a transcription of them. Rather, it is an edited collage considerably more distanced than the original texts toward which it points. To explain who wrote the text as it is, Hynes suggests that we posit a figure whom he calls Anna-the-editor, a character who has already experienced everything the Annas of the notebooks and "Free Women" sections record, and who retrospectively assembles, arranges, and edits these accounts.

To illustrate how the edited text differs from the fragments that supposedly comprise it, consider how the black notebook starts. We are not given the beginning; instead, we are presented with a description of it. Anna-the-editor, writing in brackets, tells us that the "first book, the black notebook, began with doodlings, scattered musical symbols, treble signs that shifted into the sign $£$ and back again; then a complicated design of interlocking circles, then words:]" (p. 56, emphasis added). The semiotic level at which the black notebook began before it moved into language is thus suppressed, since in our edited version everything has been transcribed into words, even the nonverbal symbols. One way to understand this transposition is to suppose that it is a recuperation of the novel's 
traditional retrospective function that was apparently lost in the exploding fragmentation recorded within its parts. This recuperation in turn depends on the recovery of a subjectivity unified enough to engage in retrospection, that is, Anna-the-editor. In this reading, both Anna-the-editor and her completed text are wholes that contain but are not reducible to the sum of their parts.

This is not the whole story, however, for it does not explain the peculiarly parodic nature of the ending. Nor does it adequately recognize that the description of the notebooks that Anna-the-editor gives us is in many ways a diminished, attenuated version of what actually reading them would have been. The experience of moving through the notebooks, of encountering the transitions from one kind of handwriting to another, from handwriting to pasted clipping, from clear text to brackets, from brackets to canceled text, would surely have been different not just in degree but in kind from the information Anna-the-editor gives us. Thus as readers, we undergo the alienation that Benjamin identifies as characteristic of an information age, because we are reduced from experiencing the texts directly to being told about them by Anna-the-editor. This implies that the recuperation of a unified subjectivity and a retrospective novelistic function are not in fact recoveries of what had been lost, but a simulation that is essentially different from the original.

Break/Down/Up;

or, What Happened at the Bifurcation Point?

In her Introduction, Lessing says that the plan of The Golden Notebook is to document the encroaching presence of chaos, until in the inner "Golden Notebook" even the traditional forms of time and space break down; out of this chaos something new is to emerge. The question that comes sharply into focus as breakdown approaches is whether individual consciousness, as it has been traditionally constituted in the Western tradition, can provide the unified context necessary to bring these splintering fragments together. Or more accurately, since what we are reading is a fictional representation of that consciousness, whether the conventions of realistic narratives can continue to constitute individual consciousness as a putative source for "genuine art," or whether the disintegration of the 
subject will precipitate a crisis in representation which makes a traditional novel impossible to write. The self-reflexive turn of this construction, which links the writing subject with the subject of the writing, becomes explicit in the inner "Golden Notebook," which records Anna's breakdown and her entry into new visions of space and time.

Even as Anna experiences herself fragmenting into many different people, a countermovement begins that emphasizes fusion and wholeness. The invisible "projectionist," running the film that is at once Anna's life and her writing, screens a part she has not seen before which shows Michael merging with his fictionalized double, Paul, to create a new person with "the heroic quality of a statue" (p. 6I8). This figure, himself an image of art joined with life, gives Anna a message that valorizes her earlier attempt to join the local with the global in the naming game. He tells her that he and she will never be great men or women, envisioning a new future for humankind. Rather, they are destined to be "boulder-pushers," using "all our energies, all our talents, into pushing that boulder another inch up the mountain. And they [the great men] will rely on us and they are right; and that is why we are not useless after all" (p. 6r8). The thought that she is a Sisyphean "boulder-pusher" remains with Anna throughout this section. It is echoed and reinforced in another playback of the film, when she recognizes for the first time how thoughtlessly cruel she has been to people around her. She realizes that "the film was now beyond my experience, beyond Ella's, beyond the notebooks, because there was a fusion; and instead of seeing separate scenes, people, faces, movements, glances, they were all together." She understands that the film is about "a small painful sort of courage which is at the the root of every life, because injustice and cruelty is at the root of life." She recognizes that she had concentrated on the "heroic or beautiful or the intelligent" because she could not accept this truth, and as a consequence missed seeing the central importance of "the small endurance that is bigger than anything" (pp. 635-636). In this new perception, scaling back her ambition does not signal failure. Rather, it represents a necessary acceptance of the local. It answers Maryrose's question, "What's wrong with not settling for second-best?" with the insight that to refuse the local is arrogance, not purity.

From the perspective of the "boulder-pushers" passage, readers 
who object to the conventional nature of the ending are clinging to the illusion of dramatic revolution rather than accepting the reality of incremental change. Throughout, there have been intimations that revolutions too often turn out to be merely changes in personnel which leave underlying power structures intact, like the prisoner and guard who change places in Anna's nightmare (p. 345). Real change, Lessing seems to suggest, comes only when one devotes one's efforts to improving (however slightly) the place where one is, rather than retreating to global visions of what the world should ideally be like.

And yet this is hardly the whole story. Certainly it is not the most interesting story. It elides the deeper questions raised by Anna's encounter with chaos, and provides no satisfactory account of the extraordinarily complex structure of the novel. If Anna-the-editor is reducible to a boulder-pusher, why would she need to create so incendiary a form and resurrect so many dangerous possibilities? In her Introduction, Lessing skips rather lightly over these issues. She asserts that "in the inner Golden Notebook things come together, the divisions have broken down, there is formlessness with the end of fragmentation-the triumph of the second theme, which is unity" (p. vii). Compare this description with the text we have; is it adequate? After the searing intensity of Anna's psychotic episodes with Saul, surely most readers will find the end of the inner "Golden Notebook" attentuated and laconic by comparison. The final "Free Women" section is even more of a disappointment, with Molly retreating into the bourgeois respectability of a marriage to a "progressive businessman" who resembles her ex-husband, Richard, and Anna announcing that she intends to work as a marriage counselor with Dr. North, ${ }^{7}$ join the Labour party, and teach night classes twice a week for delinquent youngsters. For a character who has represented herself as having undergone radical personality transformations, including fragmenting into multiple personae and losing all sense of conventional time and space, these are mild decisions indeed. Rather than displaying increased complexity, the closing "Free Women" section seems to be a parodic recapitulation of the opening

'Dr. North's name seems to indicate that he is the model for the fictional Dr. West, for whom Ella works. If we may judge him by the portrait of Dr. West that Ella draws, Anna's decision to work with Dr. North to save troubled marriages seems even more questionable than it would otherwise appear. 
"Free Women" chapter, demonstrating the complete futility of all that has happened between them.

In her r97 I Introduction, Lessing does not acknowledge this as a possibility. Instead she asserts that the inner "Golden Notebook" brings the fragmented sites of The Golden Notebook together into a successful synthesis, signified by the fact that it is written jointly by Saul and Anna. At this point, Lessing writes, "you can no longer distinguish between what is Saul and what is Anna, and between them and the other people in the book." According to her, this fusion of characters "is a way of self-healing, of the self's dismissing false dichotomies and divisions" (p. viii). Lessing's representation of the text here glosses over an important distinction. It is not quite true that Anna and Saul collaborate in writing the inner "Golden Notebook." Rather, they write the imagined precursor to the text we have, the Ur-text to which our text alludes when Anna-the-editor tells us, in brackets, "[Here Anna's handwriting ended, the golden notebook continued in Saul Green's handwriting, a short novel about the Algerian soldier]" (p. 642). A summary of the novel follows, not the novel itself. Thus Anna-the-editor writes the inner "Golden Notebook," just as she has written all that has come before and after.

Lessing's elision of Anna and Saul with Anna-the-editor is significant because it points to an undecidable crux within the text. If Anna-the-editor is really Anna-and-Saul, we have no way to know that. The undecidability is made more profound by the recuperation at the end. If a new order has emerged, its nature is such as to make it indistinguishable from the old. What does it signify that success looks so much like failure, and that the emergence of a new order cannot be separated from its suppression? These questions have entered the criticism on The Golden Notebook as a debate about whether or not the ending is satisfactory. ${ }^{8}$ I want to recast the terms

${ }^{8}$ Readers who defend the ending include John L. Carey, in "Art and Reality in The Golden Notebook," Contemporary Literature I4 (I973): 437-456; Carey writes that the ending demonstrates that "to exist is better than not to exist, to struggle is better than to give in, to face the truth and live with it is the measure of an individual's maturity" (p. 454). Valerie Carnes, in "Chaos, That's the Point': Art as Metaphor in Doris Lessing's The Golden Notebook," World Literature Written in English I 5 (1976): 17-28, gives a somewhat more qualified endorsement, acknowledging that the ending is "tentative, modest, shot through with irony" (p. 27). 
of that debate by suggesting that there is a deep ambiguity about the ending which eludes an either/or resolution. Rather than a new order emerging out of chaos, it appears that the old and new orders have interpenetrated in a way that eludes rational analysis.

To tell this story, it is necessary to put aside for the moment a recuperative reading and suppose that the ending is about a radical reorganization that emerges after all. How would individual consciousness be constituted, and through what narrative and literary conventions could it be represented? A reading that attempted to answer these questions would have to be centrally concerned with form, for if a sea-change is to take place, it could be signaled only by a transformation of the premises underlying representation. Let us return to the beginning, then, and cycle through the text one more time, now taking the other path at the bifurcation point.

\section{The New Order: Emergence of a Simulacrum}

In her talk with Molly at the beginning of The Golden Notebook, Anna says that a well-known painter has announced that he is giving up painting because "the world is so chaotic art is irrelevant" ( $p$. 42). The statement recalls Morse Peckham's thesis in Man's Rage for Chaos (1967) that the purpose of art is to break paradigms and assault established conventions, so that the replicating mechanisms that ensure the stability of the species will be invested with the necessary flexibility to ensure that change can also happen. And yet art also creates form; indeed, one might say that the essence of an artistic creation is its status as a shaped artifact. An art object without form is a contradiction in terms. Even if its form is such as to convey an impression of formlessness, it has still been designed and shaped with this purpose in mind.

Throughout The Golden Notebook, Anna wrestles with the transformation that takes place when fleeting thoughts are transcribed

Typical of readings that find the ending disappointing is Kathleen McCormick, "What Happened to Anna Wulf: Naivety in The Golden Notebook," Massachusetts Studies in English 8 (1982): 56-62; McCormick says that the "reader is engaged, but ultimately disappointed by Anna's near-achievements" (p. 57). 
into a text. Once on the page, the words seem more fixed than they ever did in consciousness-more formed, especially when they are thoughts about chaos. In trying to explain to Mrs. Marks why she does not write for publication any more, Anna refers to this transforming process as a falsification, insisting, "It's a question of form." She goes on to say that contemporary readers will tolerate or welcome almost any moral aberration in their reading; but what "they can't stand is to be told it all doesn't matter, they can't stand formlessness" (p. 474). In The Golden Notebook, Lessing confronts the possibility that formlessness is truer to this cultural moment than form. However, she has only the inherited forms of her cultural traditions with which to convey this vision. Richard's pious hypocrisy that "I preserve the forms" (p. 26) resonates until, near the end, it becomes Anna's explanation for why she will write The Golden Notebook as she does.

The moment when Anna conceives the text, and therefore the moment when Anna-the-editor is conceived, is represented within the text. It occurs when Saul gives Anna the first sentence of her novel, which is also the first sentence of The Golden Notebook. The structure is thus self-reflexive as well as recursive, in the sense that the parts (the Annas of the different sections, the transcriptions of the notebooks) are contained within the whole at the same time that the whole (Anna-the-editor, The Golden Notebook as a finished text) is mirrored within the part.

One of the characteristics of a self-swallowing structure is infinite regress. Recall Borges's meditation on The 1001 Nights. ${ }^{9}$ Borges notes that enfolded among the tales that Scheherazad tells is the most dangerous story of all. It occurs on Night 602, the evening when she decides that she will tell her own story. One can imagine her starting the story; when she arrives at the point where she decides to tell her story, however, she slips from the original recitation into an inner story that starts the narrative anew. From this inner story, she will at the crucial moment of self-reflexive mirroring slip into a doubly interior story, and from there into a triply interior

"Jorge Luis Borges, "The Translators of The 1001 Nights," pp. 73-87, especially 86, and "Partial Enchantments of the Quixote," pp. 232-234, especially 234, both in Borges, $198 \mathrm{I}$. 
story. . . . Unless some outside force intervenes, she will be caught in an endless recursion, each story nested inside its predecessor like an infinite series of Chinese boxes. "Does the reader perceive the unlimited possibilities of that interpolation, the curious danger - that the Sultana may persist and the Sultan, transfixed, will hear forever the truncated story of The 1001 Nights, now infinite and circular," Borges asks ( $198 \mathrm{I}: 234$ ).

In The Golden Notebook, the moment of slippage is not so dangerous, for it is only the first sentence that is repeated, not the entire story. Coming at the end of the inner "Golden Notebook," however, this moment is enough to raise questions about the status of the "Free Women" section that follows. What if at the self-reflexive junction the narrative slips from the epistemological framework that contains the story up to that point and enters another frame in which the forms may be perserved but the entire orientation is different? In that case, the final "Free Women" section would be neither a realistic working out of scaled-down expectations nor a parody of the initial "Free Women" chapter, but a simulacrum, a copy that has no original. It has no original because it does not exactly repeat either the beginning or the penultimate inner "Golden Notebook." Nevertheless, it is a copy in the sense that it is caught in a recursive loop. As a result, the text is a representation of its failure to represent what it points toward but can never reach.

Anna says as much as she approaches the moment when the text will swallow itself like the uroborus, the snake with its tail in its mouth. "During these last weeks of craziness and timelessless," she writes, "I've had these moments of 'knowing' one after the other, yet there is no way of putting this sort of knowledge into words. Yet these moments have been so powerful, like the rapid illuminations of a dream that remain with one waking, that what I have learned will be a part of how I experience life until I die. Words. Words. I play with words, hoping that some combination, even a chance combination, will say what I want. . . ." If we take Anna at her word(s), whether the ending is a simulacrum or a representation is inherently undecidable, since the informing experience that distinguishes the two is itself beyond words. "The people who have been there, in the place where words, patterns, order, dissolve, will know what I mean and the others won't," Anna writes (pp. 633-634). 
Even though the confirming experience cannot be shared through language, it effects a change that will make the illuminati cognizant that what follows is not the thing itself, or a representation of the thing, but a simulacrum. This knowledge registers itself as irony. "But once having been there there's a terrible irony, a terrible shrug of the shoulders, and it's not a question of fighting it, or disowning it, or of right or wrong, but simply knowing it is there, always. . . . All right, I know you are there, but we have to preserve the forms, don't we?" (p. 634). In this view, the conundrum of how to create a form that will represent formlessness, how to forge a context that will make sense of a context of no context, is to create a pastiche whose fragmentation accelerates until it implodes into a new kind of form, the simulacrum. This is the transformation that Anna senses in the depth of her madness, when she writes that something "has to be played out, some pattern has to be worked through" (p. 583).

To position this reading more fully, I want to compare and contrast it with Jean Baudrillard's (I98I, I983) concept of the simulacrum. To illustrate what Baudrillard means by a simulacrum, consider the following progression. In ancient times, animals were killed for food and their skins were used as warm, utilitarian coverings. As animals grew scarce, their furs became status symbols, signifying wealth and privilege. Since there were not enough real furs to go around, simulated furs were produced to fill the demand create by those who aspired to the illusion of wealth but did not possess the money to buy real furs. At first these synthetic furs were marketed as copies of the originals. As more and more copies were produced, however, they began to compete on the basis of their superiority to other copies. At some point the original disappeared altogether, no longer serving to anchor the chain of these proliferating signifiers. Then the copies "imploded" into a new order of nonreferential signification that operated by displacement rather than representation. Baudrillard calls this the "hyper-real," a theater where everything is at once nonreferential and as real as anything else.

The emergence of an information age was crucial in bringing about this implosion, for it provided the technology that distanced an object so far from its putative origin that the origin could not be recovered, even in theory. A capitalistic economy was also impor- 
tant, for the displacement of desire onto a succession of copies created the expanding commodity market that capitalism needs to stave off collapse. It goes without saying that Lacanian psychology and poststructural linguistics were also important precursors to the idea of the simulacrum, for they carried the absence of origin into the formation of the psyche and the structure of language.

To connect the simulacrum with Lessing's text, consider another progression. One of the earliest successful children's television shows was Howdy Doody. Howdy was technologically simple. He was an obvious if crude copy of a human being, and he needed a human nearby to manipulate him and supply him with his voice. Howdy was soon superseded by the cartoon programs he introduced, which were at a further remove technologically from their human inventors, and also at a further remove physically from the human form. With computer animation came figures that were increasingly less anthropomorphic, including characters that combined human and machine parts. Finally Max Headroom arrived on the scene. Max was not a copy of a human being, as Howdy was, but a simulacrum. Max's essential quality was his nonreferential status with respect to the human. Since he lived in the TV sceen, he was both a representation and the thing itself. This disturbing convergence of the representation with its referent is characteristic of the simulacrum. Once we have entered into this space, the distinction between the copy and the original ceases to have meaning. At this point we live within the hyper-real, and ourselves have become it.

In suggesting that the final "Free Women" section is a simulacrum, I mean to invoke the associations with which Baudrillard invests the term, for I think they are nascently present in Lessing's text. If Anna-the-editor is not a scaled-down version of the Annas who wrote the notebooks, she must be a simulacrum, a copy that has no original. Similarly, if The Golden Notebook is identical neither with its parts nor with a synthetic, integrated whole toward which it nostalgically gestures, then it too is a copy with no original. This reading brings out the most disturbing and refractory aspects of The Golden Notebook, for it places the text along a path that Baudrillard and others would develop further.

I do not want to push the analogy too far, because The Golden Notebook also differs from Baudrillard's simulacrum in important 
ways. For example, although the reality that the final "Free Women" section gestures toward cannot be represented, it may nevertheless exist, whereas Baudrillard's point is that reality and our representations of it have collapsed into the same space. Whether this implosion actually takes place in The Golden Notebook remains undecidable, an indication that Lessing's text is caught between two paradigms. It has no choice but to reenact the old, for those are the only forms available; and yet by pushing the forms to (and perhaps beyond) the limits of their assumptions, it gestures toward the new.

One of the insights that Anna has when she is listening to the "projectionist" is how thin the line is between her own writing and the "style of the most insipid coy woman's magazine" - perhaps the magazine Ella works for (p. 620). Changing "a word here and there only," Anna transforms her style into a parody of her writing and of herself. That thin line keeps The Golden Notebook from entering the hyper-real. In being able to distinguish her authentic voice from a parody, Anna retains a sense of the reality of her subjectivity, and consequently of its potential as a source for her art. Thus the ending can be read as a reinscription of the values that underlie the realistic novel, and more generally of the assumptions that make modernist representations possible. But it can also be read as signaling the transformation of the text into a postmodern collage of information, in which parody does not exist because the center did not hold. The ambiguity points toward a profound duality within the new paradigms-whether they imply the renewal of human subjectivity as it has traditionally been constituted or its demise. 